\title{
REVIEW OF A MEMBRANE TECHNOLOGY IN WATER SUPPLY SYSTEMS - NANOFILTRATION
}

\author{
KALYANIKATHANE ${ }^{1}$, S.R. KHANDESHWAR ${ }^{2}$ \& ANIKET PATHADE ${ }^{3}$ \\ ${ }^{1,2}$ Ceinsys Tech Ltd, Nagpur, YCCE, Nagpur, India \\ ${ }^{3}$ Research Scientist, Jawaharlal Nehru Medical College, Datta Meghe Institute of Medical Sciences, Sawangi, Wardha, India
}

\begin{abstract}
During the period of 1970s, the Reverse Osmosis membranes were developed which comprised of higher operating pressures. The consequence of this was the considerable increase in energy cost. As a result, low-pressure reverse osmosis membranes were developed and came to be known as Nanofilter (NF) membranes ${ }^{1,2}$. Through the late 1980s, Nanofilters came into establishment. From early 1990s, these had become common with varying applications to be found. The features of this membrane technology falls between ultrafiltration and reverse osmosis. Even though RO membranes take over the desalinization of marine water, Nanofiltration has widespread use in wastewater treatment, industrial applications for eliminating ion selections, and organic substances ${ }^{3,4.5}$. It is most often used with low total dissolved solids water such as surface water and fresh groundwater with the purpose of water softening and removal of disinfection byproduct precursors such as natural organic compounds and synthetic organic compounds. Depending on several factors considering the quality of the water in use, treatment capacity, the purpose of treatment, and the requirements for durability, the selection of NF membranes can be made over other treatment processes ${ }^{6,7}$.

KEYWORDS: groundwater, durability \& Nanofilter
\end{abstract}

Received: Jun 09, 2020; Accepted: Jun 29, 2020; Published: Aug 11, 2020; Paper Id.: IJMPERDJUN2020717

\section{INTRODUCTION}

\section{Objective}

The objective of this study is to review implementation and utilization of NF membranes for the purpose of water treatment.

\section{Mechanism}

NF membranes are made as flat sheets which are rolled into spiral wound module format. Within the spiral module, the feed stream is separated into two new liquid streams. The retentate contains the larger molecules that cannot pass through the membrane owing to the pore size constraint ${ }^{8,9}$. The solvent fluid can pass through the membrane and forms the permeate. The concentrate has the reject molecules.Having slightly charged surface of the membrane, the dimensions of pores close to dimensions of ions, the charge interaction takes place. It, therefore, can be used to separate ions with different valencies ${ }^{10.11}$.

\section{Materials used}

Typically, NF membrane is made with materials like polymers including polyethersulfone, polysulfone, polyphenylsulfone, polytetrafluoroethylene, polyvinylidene fluoride, nylon, polypropylene, cellulose acetate(CA), regenerated cellulose, ceramic and cintered metals, carbon nanotubes. The pore size to which a NF membrane 
corresponds to, ranges between molecular weight of 300-500 gms/mol. Thus, separation from components of higher molecular weight can be achieved ${ }^{12,13,14}$.

\section{Separation}

During normal operation, pressure is applied to the liquid feed by a pump and this pressure pushes the molecules through the membrane. Molecules with particle size less than that of the pore size of NF membrane pass through the membrane $e^{15,16,17}$. If the pore size is increased, then both the solvent molecules and concentrate molecules can pass through the membrane whereas the heavier molecular weight particles are kept in retentate. Thus, membranes of different pore size can be used to carry out different types of separations ${ }^{18,19}$.

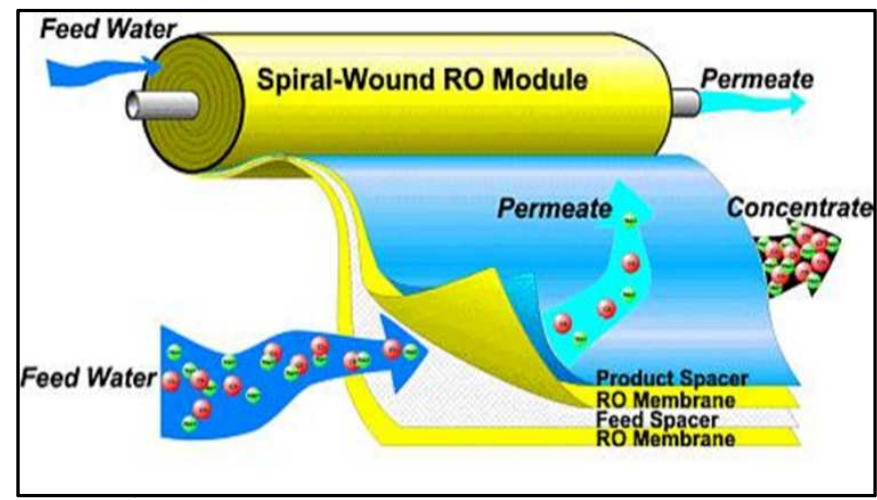

Figure 1

\section{Construction}

A typical spiral wound module contains several membrane leafs that are wrapped around the permeate tube. Each leaf contains several materials, two layers of membrane, a feed spacer to distribute the feed flow over the membrane surface, and a permeate spacer to allow liquid that is permeated through the membrane to float down the leaf to the permeate tube.

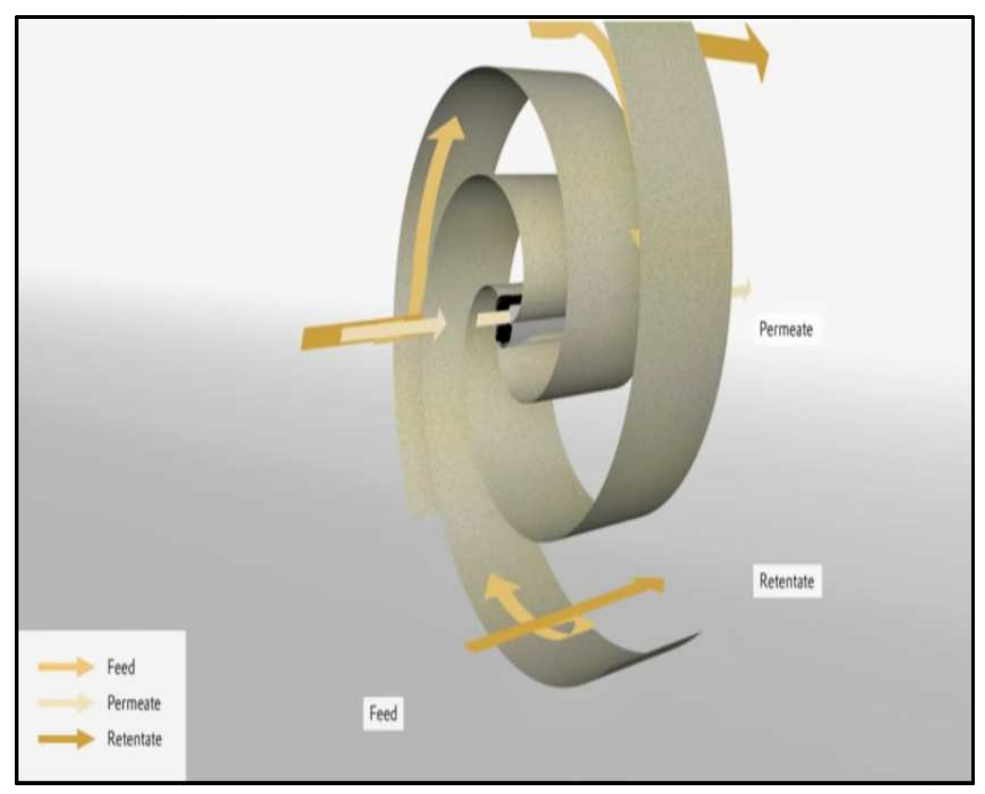

Figure 2 


\section{Fluid_Dynamics}

The figure below shows how the liquids flow inside the spiral wound module. The feed flow shows the representation by the combined brown and sand coloured arrows, which flows along the length of the module parallel to the permeate tube. The liquid permeating through the membrane represented by the sand-colored arrows flows in a spiral flow path along the permeate spacer inside the membrane leaf to the permeate tube. Finally, the retentate represented by the brown arrow flows along the length of the module parallel to the permeate tube and leaves the module.

\section{RESULTS}

As the mechanism of this technology shows how the rejection of the specific molecular weight components from the feed liquid is achieved through the $0.01 \mu-0.001 \mu$ pore size of the membrane, Nanofilters can cause elimination by retaining scale-forming, hydrated divalent ions (e.g. $\mathrm{Ca}^{2+}, \mathrm{Mg}^{2+}$ ) while passing smaller hydrated monovalent ions. The main highlight of this technique is retainment of vital, optimum TDS with essential minerals for human body, which otherwise gets totally removed by RO membrane ${ }^{20}$.

\section{CONCLUSIONS}

NF membranes can be more effective than other technologiesin the treatment of drinking water, especially with the removal of color, hardness and DBP precursors. The reduction of wastage and reuse of water can be achieved. The reject water after the treatment using NF membranes is comparatively less than that obtained from RO membranes. This results in the reduction of overall cost of operation, lower energy consumption and chemical-free filtration.

\section{REFERENCES}

1. Lu X, BianX et al. Preparation and characterizationof NF composite membrane, J. Membr. Sci. 2002; 210: 3-11.

2. Van der BruggenB, Vandecasteele C. Removalof pollutants from surface water and groundwater bynanofiltration: overview of possible applications inthe drinking water industry, Environ. Poll.2003; 122: 435-445.

3. Gaddamwar, Sagar S., Aanad N. Pawar, and Pramod A. Naik. "CFD Analysis of Membrane Helical Coil For Optimization of High Pressure And Temperature of Syngas in Underground Coal Mines." International Journal of Mechanical Engineering and Technology (IJMET) 9.11 (2018): 1080-1088.

4. Conlon W, McClellan S. Membrane softening:treatment process comes of age, J. AWWA. 1989; 81: 47-51.

5. Schaep J, Van der Bruggen B, S. Uytterhoeven et al. Removal of hardnessfrom groundwater by nanofiltration, Desalination. 1998; 119: 295-302.

6. Sombekke H, VoorhoeveD et al. Environmental impact assessment of groundwatertreatment with nanofiltration, Desalination. 1997; 113: 293-296.

7. Girish, C. R. "Review of various technologies used for biodiesel production." Int. J. Mech. Prod. Eng. Res. Dev 9.3 (2019): 1379-1392.

8. Watson B, Hornburg C. Low-energy membranenanofiltration for removal of color, organicsand hardness from drinking-water supplies,Desalination. 1989; 72: 11-22.

9. Fu P, Ruiz H et al. Selecting membranes for removing NOM and DBPprecursors, J. AWWA. 1994; 86: 55-72. 
10. Gaddamwar, Sagar S., Anand N. Pawar, and Pramod A. Naik. "An Optimization of High Pressure and Temperature of Syngas in Underground Coal Mines by Using Cfd Analysis of Membrane Serpentine Tube."International Journal of Mechanical and Production Engineering Research and Development (IJMPERD) 9. 1, Feb 2019, 617-624

11. Fu P, Ruiz $H$ et al. A pilot study on groundwaternatural organics removal by low-pressure membranes,Desalination. 1995; 102: $47-56$.

12. Jacangelo J, TrussellR et al. Roleof membrane technology in drinking water treatmentin the United States, Desalination, 113 (1997) 119-127.

13. Escobar I, Hong $S$ et al. Removal ofassimilable and biodegradable dissolved organiccarbon by reverse osmosis and nanofiltration membranes, J. Membr. Sci. 2000; 175: 1-17.

14. Khalik A, Praptowidodo V. Nanofiltration fordrinking water production from deep well water. Desalination. 2000, 132: 287292.

15. Patel, Nilesh A., and Jigisha U. Pandya. "Vibrating Membrane Problem Solved Using Spline Collocation Method with Dirichlet Conditions."

16. Alborzfar M, Escande $K$ et al. Removal ofnatural organic matter from two types of humicground waters by nanofiltration, Water Res. 1998; 32: 2970-2983.

17. Gorenflo A, Veliizquez-Padrh D et al. Nanofiltration of a German groundwater of highhardness and NOM content: performance and costs. Desalination. 2002; 151: 253-265.

18. Van der Bruggen B, Schaep J et al. Nanofiltration as a treatmentmethod for the removal of pesticides from groundwaters, Desalination. 1998; 117: 139-147.

19. Van der Bruggen B, Everaert $K$ et al. Application of nanofiltration forthe removal of pesticides, nitrate and hardness fromground water: retention properties and economicevaluation, J. Membr. Sci. 2001; 193: 239-248.

20. Rani, K., et al. "Biological Treatment Of Distillery Waste Water-An Overviewll." International Journal of General Engineering and Technology 2.4 (2013): 15-24.

21. Wittmann E, Cote $P$ et al. Treatment of a hard borehole water containinglow levels of pesticide by nanofiltration. Desalination. 1998; 119: 347-352.

22. Kiso Y, Mizuno A et al. Rejection properties ofpesticides with a hollow fiber NF membrane (HNF-1), Desalination. 2002; 143: 147-157.

23. Berg P, HagmeyerG et al. Removal ofpesticides and other micropollutants by nanofiltration. Desalination. 1997; 113: 205208.

24. Montovay T, AssenmacherM et al. Elimination of pesticides from aqueous solution bynanofiltration, Magyar KemiaiFolyoirat, 1996; 102: 241-247.

25. Ducom G, Cabassud C. Interests and limitationsof nanofiltration for the removal of volatile organiccompounds in drinking water production, Desalination. 1999; 124: 115-123. 